\title{
The relationship between social status, behaviour, growth and steroids in male helpers and breeders of a cooperatively breeding cichlid
}

\author{
Nicole Bender ${ }^{\mathrm{a}, *}$, Dik Heg ${ }^{\mathrm{a}}$, Ian M. Hamilton ${ }^{\mathrm{a}}$, Zina Bachar ${ }^{\mathrm{a}}$, \\ Michael Taborsky ${ }^{a}$, Rui F. Oliveira ${ }^{b}$

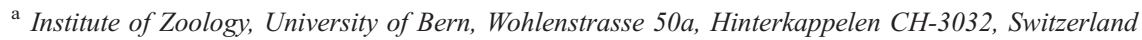 \\ ${ }^{\mathrm{b}}$ Unidade de Investigação em Eco-Etologia, Instituto Superior de Psicologia Aplicada, Lisboa 1149-041, Portugal
}

Received 26 August 2005; revised 10 February 2006; accepted 27 February 2006

Available online 19 April 2006

\begin{abstract}
We tested whether subordinate helper males of the Lake Tanganyika cooperatively breeding cichlid Neolamprologus pulcher show elevated excretion levels of the stress hormone cortisol and reduced levels of 11-ketotestosterone and testosterone when living in groups with a small breeder male, compared to similar helper males living in groups with a large breeder male, in a full-factorial repeated measures experimental design. We also measured the same hormones in breeder males with and without helper males. Previous research showed that the size difference between large male helpers and male breeders in groups of this species influences behaviour and growth decisions. Contrary to our expectation, no effect of the size-difference between helper males and breeder males on helper hormone levels was detected. Furthermore, helper males had similar hormone excretion levels to those of size-matched breeder males without helpers, and to small breeder males. There was no influence of egg laying on breeder male and helper hormone levels during the experiment. Interestingly, all three hormone levels were significantly lower in helpers showing elevated levels of submissive behaviour towards the breeders, independently of the size of the breeder males. The low cortisol levels suggest that helper males can successfully reduce stress by appeasing breeder males through submission. Furthermore, helper males showing a high level of submissive behaviour had lower levels of androgens than less submissive helpers, suggesting a lower reproductive potential in submissive helpers. We propose that helper submission may be used as an honest signal of reduced interest in reproduction towards the breeder male in this species.
\end{abstract}

(C) 2006 Elsevier Inc. All rights reserved.

Keywords: Social dominance; Steroid hormones; Androgens; Submissive behaviour; Honest signals; Fish; Neolamprologus pulcher

\section{Introduction}

The relationship between hormones and social behaviour in vertebrates has been shown to be strong, bidirectional and reciprocal (Wingfield et al., 1990; Wilson, 1993; Oliveira et al., 2001a, 2001b; Oliveira, 2004). In greylag geese (Anser anser), for example, there is an intricate relationship between dominance status and steroid hormone levels, depending on various factors such as territoriality, season and social stress (Kotrschal et al., 1998). In fish, dominant males often have higher androgen plasma levels than subordinates, but this relationship can be reversed experimentally by manipulating

\footnotetext{
* Corresponding author. Fax: +41 316319141.

E-mail address: nbender@ispm.unibe.ch (N. Bender).
}

social status. This suggests that the steroid plasma levels are a result rather than a cause of the social position (Cardwell et al., 1996; Oliveira et al., 1996). On the other hand, experimental administration of androgens to male fish enhances their aggressiveness and dominance (Ros et al., 2004).

Mating and brood care patterns in particular are important social factors influencing hormone levels in fish (Oliveira et al., 2001a, 2001c; Oliveira, 2004; Hirschenhauser et al., 2004; Ros et al., 2004). A special form of social organisation is the cooperative breeding groups with helpers at the nest, where socially subordinate members of the group (so-called "helpers") assist breeders in caring for offspring (Taborsky and Limberger, 1981; Riedman, 1982; Brown, 1987; Taborsky, 1994; Cockburn, 1998; Solomon and French, 1997; Hatchwell and Komdeur, 2000; König and Dickinson, 2004). Subdominants 
in mammal and bird societies generally have lower androgen levels than dominants, except when subdominants participate in reproduction. This may reflect an intriguing trade-off in the androgen physiology of helpers: on the one side high androgen levels allow for participation in reproduction, while on the other side they may increase the risk of being expelled from the territory by the dominant male (Reyer et al., 1986; Schoech et al., 1991; Wingfield et al., 1991; Vleck and Brown, 1999; Oliveira et al., 2003).

In the cooperatively breeding cichlid Neolamprologus pulcher, an endemic substrate breeder of Lake Tanganyika, East Africa, several size cohorts of helpers usually coexist in a family group, participating in all duties of the breeding pair, including defence of the territory against conspecific and heterospecific intruders, digging out shelters and direct brood care (Taborsky and Limberger, 1981; Taborsky, 1984, 1985; Balshine et al., 2001; Dierkes et al., 2005; Stiver et al., 2005). Male helpers may share paternity with the breeder male (Dierkes et al., 1999), and Oliveira et al. (2003) reported similar levels of testosterone (T) and 11-ketotestosterone (11KT) in both breeder males and helper males in this species. Thus, in $N$. pulcher, there is a potential for conflict between helpers and breeders about the possible participation of helpers in reproduction. Breeder males threaten helpers with aggression and the risk of expulsion (Dierkes et al., 1999; Skubic et al., 2004), while helpers attempt to appease the breeders and reduce the risk of expulsion from the territory by helping and displaying submissive behaviour, depending on environmental constraints (Taborsky, 1985; Balshine-Earn et al., 1998; Heg et al., 2004a; Bergmüller and Taborsky, 2005; Bergmüller et al., 2005). Buchner et al. (2004) found higher cortisol (F) plasma levels in dominant individuals than in subordinates in $N$. pulcher, confirming a general rule found in many mammal and bird societies, where paternity is shared by dominants and subordinates and the social situation is therefore stressful for the dominants (Schoech et al., 2004).

The delicate social balance between breeders and helpers in $N$. pulcher is maintained because the benefits of group living outweigh the costs of competition among group members (Taborsky, 1984, 1985; Dierkes et al., 1999; Bergmüller and Taborsky, 2005; Brouwer et al., 2005; Heg et al., 2005). N. pulcher is an excellent model system to study the complex relationships between social structure, behaviour and hormone levels, because it allows experimental manipulations of social structure under controlled conditions (Taborsky, 1984, 1985; Heg et al., 2004b; Bergmüller et al., 2005).

In the present study, we manipulated experimentally the potential for conflict between breeder males and helpers by combining either small or large breeder males with adult male helpers in experimental families. We monitored behavioural interactions over the duration of the experiment (Hamilton et al., 2005) and after 1 and 2 months we recorded the growth rate of helper males and measured T, 11-KT and F excretion levels in breeder males and helper males.

This approach allowed us to test experimentally predictions regarding the interaction between conflict, hormones and social behaviour. Our results have been presented in three parts. First, we expected the potential for conflict between breeder males and helper males to increase when the size difference between them was small, resulting in increased breeder aggression towards the helper, whereas the helper should show more helping and submissive behaviours to appease the breeder (see Bergmüller and Taborsky, 2005). We found only a rise in submissive behaviour of helpers, and that they stayed further away from the breeding shelter, but no response of breeder aggression levels (Hamilton et al., 2005). Second, as under certain conditions fish can adapt their growth to their social situation (Buston, 2003), we expected a reduction in growth of helpers if the size difference to breeders is small. We indeed found such strategic growth adjustments, as male helpers grew more slowly when the size difference between them and the male breeder was small (Heg et al., 2004b).

Finally, we expected a decrease of androgen levels in helpers in the case of increased conflict potential to keep the challenge to breeders low. Moreover, we expected an increase of $\mathrm{F}$ with conflict potential due to stress, while a successful resolution of conflict, e.g. by submissive behaviour, should reduce F levels. In this paper, we present the results of hormonal and behavioural data and we discuss their implications for the understanding of this complex social structure.

\section{Methods}

\section{Experimental setup}

The experiment was conducted in an octagonal ring tank (7200 1), with a total diameter of $4 \mathrm{~m}$, internal diameter of $2.2 \mathrm{~m}$ and height of $90 \mathrm{~cm}$. It was divided into 8 equal sections, each containing 5 group compartments (for details of the setup see Heg et al., 2004b). The tank was located in a climate controlled room at the Ethologische Station Hasli, University of Bern. We kept the water temperature constant at $28.0 \pm 0.4^{\circ} \mathrm{C}$. Water biochemical parameters were kept similar to the conditions of Lake Tanganyika, the day:night cycle was kept constant at 13:11 h The tank bottom was covered with $30 \mathrm{~mm}$ of sand (ca. $1 \mathrm{~mm}$ grain size) and two bottomless flowerpot halves were placed in each compartment as breeding substrate. All fish received food ad libitum and excess food was removed regularly (food delivered twice per day; 5 days per week TetraMin dry food, 2 days frozen food with Artemia spp., Daphnia spp. and mosquito larvae).

Thirty-two experimentally created breeding groups (see Heg et al., 2004b; also Taborsky, 1984, 1985) of four fish each were assembled in each compartment of the ring tank, consisting of a focal large helper male (standard length $\mathrm{SL}=40-45 \mathrm{~mm})$, a small helper male $(\mathrm{SL}=30-35 \mathrm{~mm})$, a breeding female $(\mathrm{SL}=55-65 \mathrm{~mm})$ and either a large $(\mathrm{SL}=70-75 \mathrm{~mm})(N=16$ groups $)$ or a small $(\mathrm{SL}=46-51 \mathrm{~mm})$ breeder male $(N=16$ groups). Eight breeding pairs without helpers were created in the edge compartments of each section (focal male breeders and female breeders of standard length SL $=40-45 \mathrm{~mm}$, i.e. sizematched with the large focal helpers as control for social status). The experiment was separated in two periods of 30 days each. All individuals were marked, measured and weighed at the beginning of the experiment.

Standard length and body mass were measured again after 30 days (period 1) and hormone samples were collected from all large helper males and all breeder males, including the breeding males without helpers, as described below Subsequently, all breeder males in groups were removed, and new males were added to obtain a full factorial design. Thus, there were four transitions of male breeder sizes: from large to large, large to small, small to small and from small to large (period 2, see Fig. 1). At the end of period 2 on day 60, standard length and body mass of all individuals were measured again, and hormone samples were taken from the large helpers and breeder males.

During both periods, behaviour was recorded in all families, with and without the presence of eggs. Effects of the treatments on body measurements and behaviour have been reported elsewhere (Heg et al., 2004b; Hamilton et al., 
2005). All families showed natural territory defence and breeding behaviour during the experiment. Helpers and breeders showed digging behaviour in the two pot halves, egg cleaning (both mainly by small helpers and breeder females) and territory defence along the clear partitions against members of neighbouring groups. We searched for eggs and counted them daily before removing them to reduce effects on group behaviour and composition due to expected changes with different phases of the breeding cycle (see Taborsky, 1984, 1985).

To assess whether hormone levels depended on body mass and to check for possible effects of size, breeding cycle and status, we used an independent data set of males, including 8 breeder males $(\mathrm{SL}=54.5-76 \mathrm{~mm}), 8$ helper males $(\mathrm{SL}=41-70 \mathrm{~mm})$ and 8 sexually mature but non-breeding aggregation males $(\mathrm{SL}=57.5-71.5 \mathrm{~mm})$. Breeder and helper males were kept in family tanks (100-200 1), aggregation males were kept in group tanks (200-400 1), without shelters to prevent territoriality and reproduction. If such males are given a territory and mate, they are able to reproduce within 3-7 days (personal observations). All fish were kept under the same conditions as the experimental test fish, and we measured the same steroid hormones before the start of the experiment.

\section{Hormone assays}

To allow repetitive and non-invasive measurements, steroid hormone levels were determined from fish holding water (Hirschenhauser et al., 2002; Oliveira et al., 2003) as follows: individual focal fish were placed singly in a litre of clean water for $1 \mathrm{~h}$. The clean water had the same composition as tank water and it was taken from a special pool tank which had never contained fish. To avoid contamination, all materials used were washed with ethanol and distilled water before each measurement. The water was filtered through paper filters and then passed through a solid-phase C18 extraction column (Sep Pak RP-18, Merck) to adsorb the steroids. These columns were frozen at $-26^{\circ} \mathrm{C}$ until further processing. To reduce variance due to potential diurnal hormone fluctuations, sampling was always done at the same period of day (between 11.00 and 13.00), and before feeding.

Fish release several fractions of steroid hormones into the water; the free fraction is mainly released through the gills, the conjugated fractions through

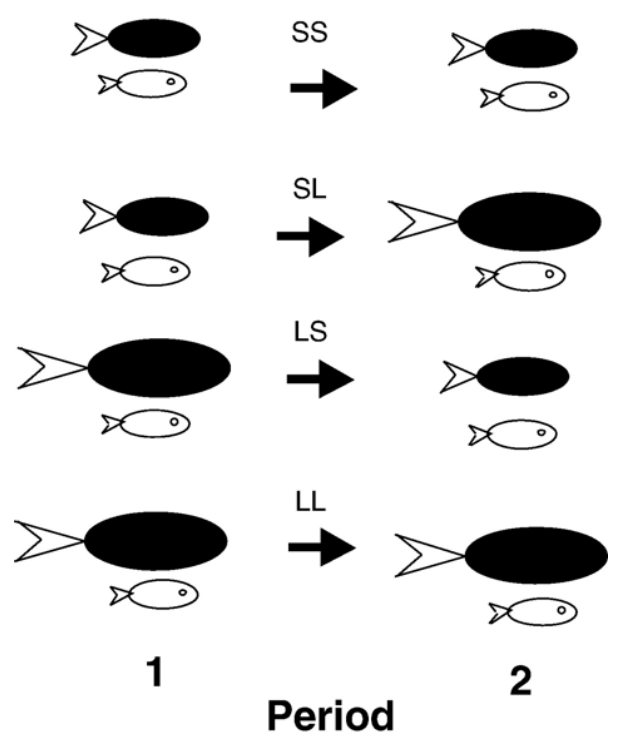

Fig. 1. Design of the strategic growth experiment. Focal large helper males (white) either helped a small or a large breeder male (both black) in the first period (1). After 30 days, all breeder males were exchanged, whereas the focal helper males, breeding females and small helper males remained (breeding females and small helper males not depicted for clarity). Again, focal large helper males either helped small or large breeder males in the second period (2). $\mathrm{SS}=$ small breeder in periods 1 and $2, \mathrm{SL}=$ small breeder male in period 1 and large breeder male in period $2, \mathrm{LL}=$ large breeder male in period 1 and 2 , $\mathrm{LS}=$ large breeder male in period 1 and small breeder male in period 2.
Table 1

Factors affecting helper male $(n=60)$ and breeder male $(n=63)$ hormone levels in the two treatments using repeated measures GLMM for the helpers and GLMM for the breeders, for each hormone separately

\begin{tabular}{|c|c|c|c|c|c|c|c|c|c|}
\hline \multirow[t]{3}{*}{ Hormone $^{\mathrm{a}}$} & \multicolumn{9}{|l|}{ Factors } \\
\hline & \multicolumn{3}{|c|}{ Constant } & \multicolumn{3}{|c|}{ Treatment } & \multicolumn{3}{|c|}{ Period $^{\mathrm{b}}$} \\
\hline & F & $d f$ & $P$ & $F$ & $d f$ & $P$ & $F$ & $d f$ & $P$ \\
\hline \multicolumn{10}{|c|}{ Helper males } \\
\hline $\mathrm{T}^{\mathrm{c}}$ & 6.8 & 1 & 0.23 & 0.002 & 1 & 0.97 & 8.1 & 1 & 0.008 \\
\hline $11-\mathrm{KT}^{\mathrm{c}}$ & 139.52 & 1 & $<0.001$ & 0.05 & 1 & 0.82 & 0.18 & 1 & 0.29 \\
\hline $\mathrm{F}^{\mathrm{c}}$ & 6.53 & 1 & 0.17 & 0.67 & 1 & 0.42 & 4.67 & 1 & 0.04 \\
\hline \multicolumn{10}{|c|}{ Breeder males } \\
\hline $\mathrm{T}$ & 3.64 & 1 & 0.31 & 0.08 & 1 & 0.78 & 0.07 & 1 & 0.01 \\
\hline $11-\mathrm{KT}$ & 69.4 & 1 & 0.08 & 0.01 & 1 & 0.92 & 2.71 & 1 & 0.11 \\
\hline $\mathrm{F}$ & 1.74 & 1 & 0.41 & 4.99 & 1 & 0.03 & 9.41 & 1 & 0.003 \\
\hline
\end{tabular}

urine (sulphated fraction) and faeces (glucuronidated fraction) (Scott and Sorensen, 1994; Vermeirssen and Scott, 1996; Ellis et al., 2004). The hormone measurements were carried out following the procedures to measure steroids from fish holding water described by Scott and Sorensen (1994) and from fish urine described by Oliveira et al. (1996). The steroids were dissolved with ethanol, and the free, sulphated and glucuronidated fractions were extracted separately. Steroids were finally quantified by previously characterised radioimmunoassay: testosterone (T) (Scott et al., 1984); 11-ketotestosterone (11-KT) (Kime and Manning, 1982) and cortisol (F) (ANTI-Cortisol, Research Diagnostics Inc.). The results of the different fractions were summed (Hirschenhauser et al., 2004).

Several groups validated the method of measuring excreted steroid hormones in fish holding water. Steroid excretion rates of goldfish (Carassius auratus) measured in holding water (Scott and Sorensen, 1994) showed to match blood plasma levels in fish receiving similar treatment (Moriwaki et al., 1991). Injecting Tilapia males (Oreochromis mossambicus) with luteinising hormone-releasing hormone (LHRH), the excretion of T and 11-KT measured in fish holding water increased (Hirschenhauser et al., 2002). Separation of fish holding water on thin-layer chromatography and assay of fractions obtained confirmed the specificity of the antisera used to measure androgens in N. pulcher (Oliveira et al., 2003). The details for antibodies' cross-reactivity have been described by Scott et al. (1984). A special concern is the measurement of F levels, as the measuring procedure itself may be a stressful event to the test animals. However, the fish behaved very calmly during measurement periods, suggesting a less stressful sampling procedure than by blood sampling. Nevertheless, the measuring time of $1 \mathrm{~h}$ allowed for stress-induced changes in $\mathrm{F}$ levels. Therefore, the F levels measured may represent a stress response of the fish rather than their hormonal baseline. In reef fishes (Chromis dimidiatus and Pseudanthias squamipinnis), it was observed that the $\mathrm{F}$ levels measured in water correlated with the social situations of these fish, with higher excretion levels in more stressed fish (Oliveira et al., 1999). In rainbow trout, there was a positive correlation between stress situation, $\mathrm{F}$ release in water and F levels in plasma (Ellis et al., 2004).

The measurement of hormone excretion levels in holding water is insensitive to short-term fluctuations in hormone levels, as shown for example in hormone levels measured from plasma, because the steroid levels accumulated in water represent the released hormones as an integral measure over the last hours.

For hormonal analysis, we used a repeated measures design for both the large helper males $(n=32 \times 2=64)$ and single breeder males $(n=8 \times 2=16)$; and a single measure design for the small $(n=32)$ and large breeders $(n=32)$, since all were exchanged for new breeder males at the end of period 1 . However, two helpers, one single breeder male and one large breeder male, had to be excluded from the analyses because of death or changed social position during 
the experiment, reducing the sample size to $30 \times 2=60$ for the helpers, $7 \times 2=14$ for the single breeder males and 31 for the large breeder males.

\section{Behavioural observations}

Focal behavioural observations of the large helper males were conducted using the software program 'The Observer 3.0' (Noldus, Wageningen, the Netherlands) by D.H. For details of the behavioural protocol, see Hamilton et al. (2005). Up to four 15-min focal observations were obtained per period and per helper male, twice when a brood was present and twice when no brood was present. Missing values occurred when groups produced no or only one brood during an experimental period. The frequency and duration of social interactions with the breeder male and with non-group members were summarised into three and two uncorrelated Principal Components, respectively, using Factor Analyses with varimax rotation and Kaiser Normalization (see Table 1 in Hamilton et al., 2005). These components can be summarised as: (1) affiliative behaviour with, (2) submissive behaviour towards and (3) received aggression from the breeder male; (4) restrained aggression (= displays) towards and (5) overt aggression towards non-group members, respectively

\section{Data analysis}

All hormone levels were expressed in $\mathrm{pg} / \mathrm{fish} / \mathrm{h}$ and were $\ln$-transformed to normalise the data (checked by Kolmogorov-Smirnov tests). Effects of egg laying on hormone levels were analysed using the outline in Crawley (2003, p. 691-695): the timing of sampling of hormones within the breeding cycle was scaled to a proportion, $t$, where a clutch occurred at $t=0$ just before sampling and $t=1$ just after sampling (i.e. $t$ denotes the proportion of days the group had advanced towards producing the next clutch). The effect of time $t$ on hormone levels was modelled using a simple trigonometric function: hormone level $=\sin$ $(2 \pi t)+\cos (2 \pi t)$. Note that clutches were removed on the day of laying, so we did not measure the hormone levels in a normal breeding cycle with the majority of eggs hatching successfully. However, we aimed to assess the necessity of a correction for hormone level variation with the breeding cycle in our

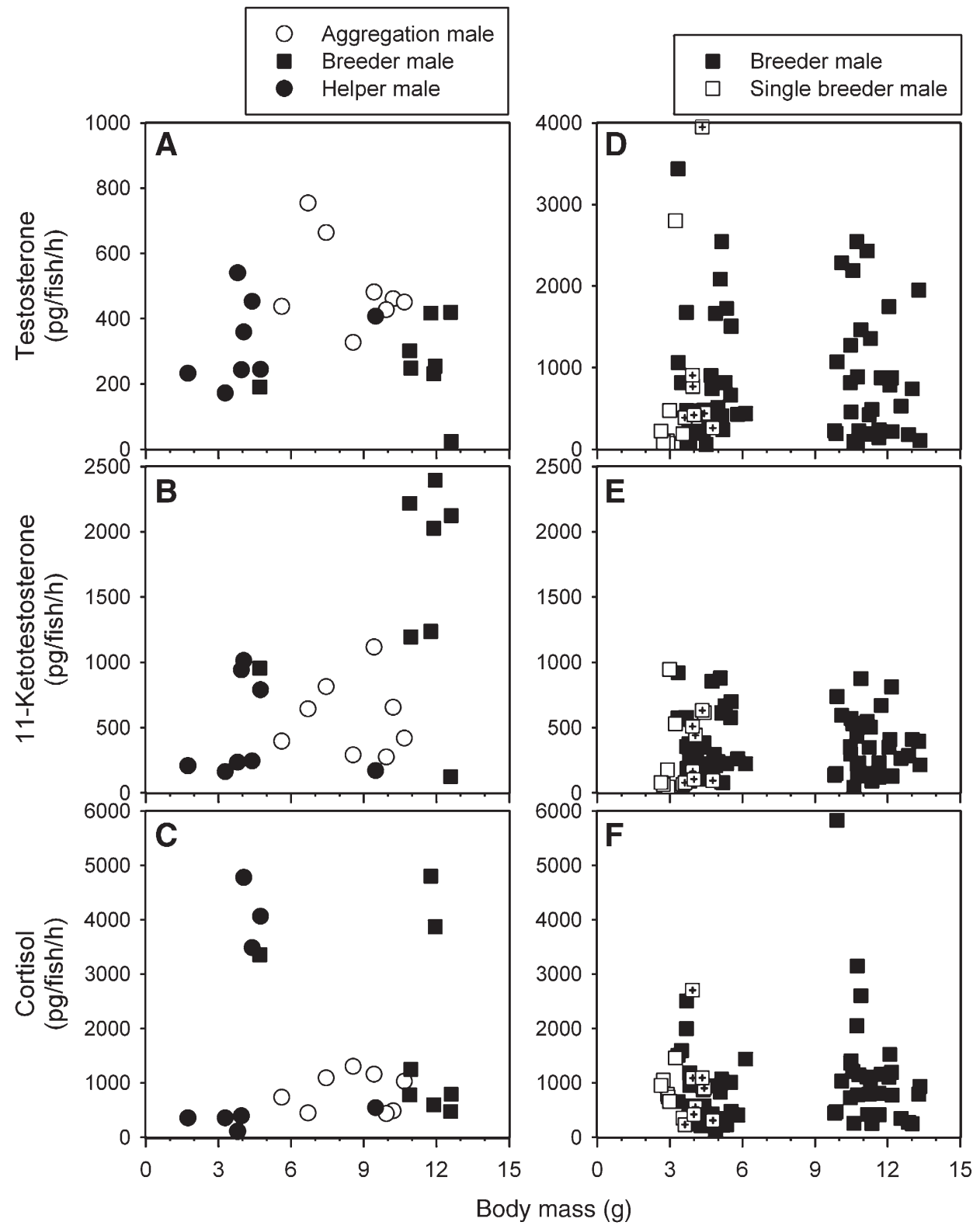

Fig. 2. Hormone levels $(\mathrm{A}=\mathrm{T}, \mathrm{B}=11-\mathrm{KT}, \mathrm{C}=\mathrm{F}$; per fish and per hour $)$ in relation to body mass of the independent data set of aggregation males, breeder males and helper males. Hormone levels $(\mathrm{D}=\mathrm{T}, \mathrm{E}=11-\mathrm{KT}, \mathrm{F}=\mathrm{F}$; per fish and per hour $)$ in breeder males used in the experiment. Crosses denote the repeated measures of the single breeder males during period 2. 
experimental design. Each of the five principal component scores was averaged per test fish and per period before relating them to the hormone levels measured at the end of each period. In total, 32 large male helpers were involved in the experiment, providing a total sample size of $32 \times 2$ periods $=64$. However, two helper males could not be used in the analyses in one period each (see above), reducing the sample size to 62 hormone measurements. Of these 62 cases, 58 individuals with behavioural observations were available. Statistical analyses were performed with SPSS 11.0 with alpha set at 0.05 .

\section{Results}

\section{Effects of body mass}

We used the independent data set of males to assess whether hormone levels depended on body mass ( 8 breeder males, with one outlying value for T, which was deleted, 8 helper males, with one outlying value for $11-\mathrm{KT}$, which was deleted, and 8 nonbreeding male aggregation members). Only 11-KT levels correlated positively with body mass (Figs. 2A-C, Pearson's correlation, T: $r=-0.038, n=23, P=0.551$; $11-\mathrm{KT}: r=-0.481$, $n=23, P=0.02$; F: $r=0.098, n=24, P=0.648)$.

The breeder males used in the present experiment showed no correlation between their hormone levels and body mass in both of the two sequences of the experiment (Figs. 2D-F, Pearson's correlation on ln-transformed data, sequence 1: T: $r=0.035, n=39, P=0.831 ; 11-\mathrm{KT}: r=-0.035, n=39$, $P=0.832 ; \mathrm{F}: r=0.116, n=39, P=0.483$. Sequence $2: \mathrm{T}$ :

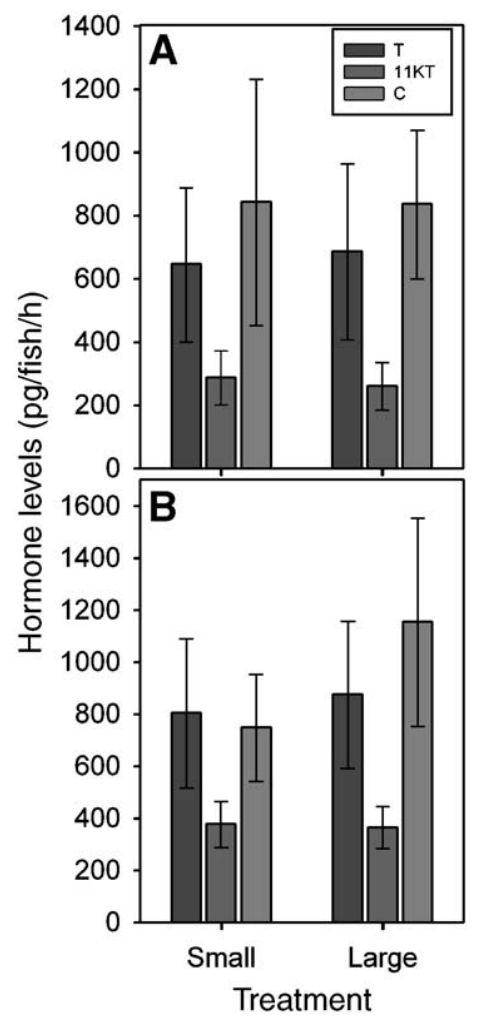

Fig. 3. Hormone levels in relation to the experimental treatments for (A) helper males ( $n=30$ for each point, repeated measures) and (B) breeder males ( $n=32$ for the small breeder males, $n=31$ for the large breeder males). Hormone levels were $\ln$-transformed before analyses, means \pm SE are shown after backtransformation. For statistics, see Table 1.

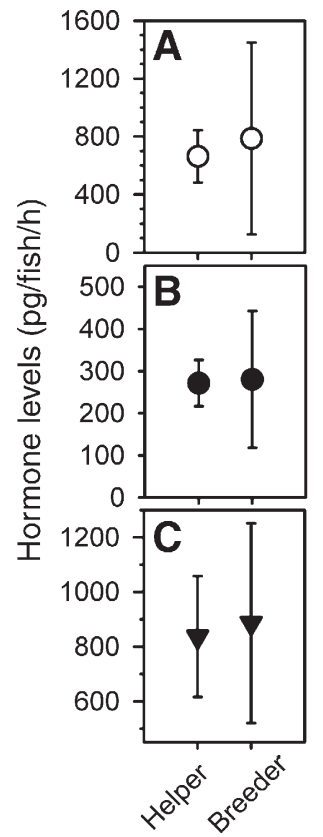

Fig. 4. Hormone levels did not depend on breeding status, comparing helper males with the single breeder males for T (A), 11-KT (B) and F (C). Note the difference in $y$ axis scaling. These males were of similar body mass and size at the start of the experiment. Hormone levels were ln-transformed before analyses, and means \pm SE are shown after back-transformation. For statistics, see Table 2.

$r=0.103, n=39, P=0.532 ; 11-\mathrm{KT}: r=0.219, n=39$, $P=0.181 ; \mathrm{F}: r=0.237, n=39, P=0.146)$.

If we corrected excreted hormone levels for body mass dividing the hormone values per gram body mass, we found a non-linear decrease with increasing body mass in both independent data sets, although only significantly so for all three hormones in the larger data set (data not shown). We therefore used excretion levels per fish and not per gram fish. Moreover, in the present study, we compared only fish of similar size, our results can therefore not be confounded by potential hormone level differences due to body size. In the only exception, when we compared large breeder males with small breeder males, we incorporated $\ln$ [body mass] as an independent covariate in the analyses to correct for eventual effects of body mass differences on hormone excretion levels. However, this analysis showed no significant effect of body mass on hormone levels, but a trend for $\mathrm{F}$ ( $d f=1$; for T: $F=0.01, P=0.92$; for $11-\mathrm{KT}$ : $F=0.32, P=0.58$; for $\mathrm{F}: F=3.9, P=0.053)$.

\section{Effects of egg laying}

The average interval between two clutches was 13.6 days ( \pm 5.4 days, range $6-31$ days, $n=119$ ). Effects of egg laying on hormone levels were assessed with a trigonometric function implemented into GLMMs [i.e. two covariates: 'timesin' = sin $(2 \pi t)$ and 'timecos' $=\cos (2 \pi t)$ and including 'period' as random effect (first or second period), for each of the three hormones, separately for breeder males and helper males]. There were no effects of egg laying on T, 11-KT and F levels for both breeder males ( $n=78$, effect of timesin: $P=0.82,0.71$ and 0.66 , respectively; effect of timecos: $P=0.58,0.55$ and 0.66 , respectively) and helper males $(n=62$, effect of timesin: 
Table 2

Breeding status effects on hormone levels, comparing helper males $(n=60)$ with the single breeder males $(n=14)$ in repeated measures GLMM analyses separate for each hormone

\begin{tabular}{|c|c|c|c|c|c|c|c|c|c|}
\hline \multirow[t]{3}{*}{ Hormone $^{a}$} & \multicolumn{9}{|c|}{ Factors } \\
\hline & \multicolumn{3}{|c|}{ Constant } & \multicolumn{3}{|c|}{ Breeding status } & \multicolumn{3}{|c|}{ Period $^{b}$} \\
\hline & $F$ & $d f$ & $P$ & $F$ & $d f$ & $P$ & $F$ & $d f$ & $P$ \\
\hline $\mathrm{T}^{\mathrm{c}}$ & 5.42 & 1 & 0.22 & 0.002 & 1 & 0.97 & 14.1 & 1 & 0.001 \\
\hline $11-\mathrm{KT}^{\mathrm{c}}$ & 89.16 & 1 & $<0.001$ & 0.17 & 1 & 0.68 & 2.66 & 1 & 0.11 \\
\hline $\mathrm{F}^{\mathrm{c}}$ & 4.44 & 1 & 0.18 & 0.55 & 1 & 0.46 & 5.3 & 1 & 0.03 \\
\hline
\end{tabular}

${ }^{\mathrm{a}}$ In $\mathrm{pg} / \mathrm{fish} / \mathrm{h}$ and $\mathrm{ln}$-transformed before analyses.

b Random effect.

c Repeated measures of 30 helper males and 7 single breeding males: corrected for random individual identity effects nested within status $(d f=35)$ : for T: $F=1.66, P=0.07$; for $11-\mathrm{KT}: F=4.09, P<0.001$; for $\mathrm{F}: F=1.88$, $P=0.03$.

$P=0.42,0.54$ and 0.21 , respectively; effect of timecos: $P=0.76,0.63$ and 0.92 , respectively). As hormone levels did not vary with egg laying, no corrections for egg laying events during the experiment were necessary in subsequent analyses.

\section{Correlations between hormones}

Individuals with high levels of T also showed high levels of 11KT and F, both for the breeder males $(n=78$, Pearson's correlations on ln-transformed data, T vs. 11-KT: $r=0.673$, $P<0.001$; T vs. C: $r=0.286, P=0.011 ; 11-\mathrm{KT}$ vs. C: $r=0.433$, $P<0.001)$ and the helper males $(n=62$, Pearson's correlations on ln-transformed data, T vs. 11-KT: $r=0.642, P<0.001$; T vs. C: $r=0.316, P=0.012$; 11 -KT vs. C: $r=0.444, P<0.001$ ).

Due to our experimental design, repeated measures of the same individuals were only performed for the helper males $(n=30)$ and the single breeding males $(n=7)$. Hormone levels were assessed for these individuals both in period 1 and 2. In general, hormone levels measured during these two periods correlated positively with each other, but only significantly so in 3 out of 6 comparisons and one tendency (Pearson's correlations, helper males $(n=30)$ : T: $r=0.12, P=0.53$; $11-\mathrm{KT}$ : $r=0.53, P=0.003$; F: $r=0.36, P=0.053$; single breeder males $(n=7)$ : T: $r=0.82, P=0.025 ; 11-\mathrm{KT}: r=0.87, P=0.012 ; \mathrm{F}$ : $r=0.11, P=0.81)$. This suggests individual consistency in hormone levels, which will be analysed in more detail below.

\section{Treatment effects}

There were no effects of breeder male size on helper male hormone levels (Table 1, Fig. 3). The helper males were sizematched in the two treatments. In contrast, small breeder males had significantly higher levels of $\mathrm{F}$ than large breeder males, while there was no difference in T and 11-KT levels between small and large breeder males (Table 1). Since here we are comparing individuals of different sizes, these effects could be due to a potential confounding effect of size on the level of secreted hormones (see above and Discussion). However, if the treatment effect was replaced by the covariate $\ln$ [body mass] in the analyses of Table $1, \ln [$ body mass] did not explain a larger proportion of the variance than treatment $\left(\ln \left[\right.\right.$ mass] effect on T: $F_{1,60}=0.01$, $P=0.92 ; 11-\mathrm{KT}: F_{1,60}=0.32, P=0.58 ; \mathrm{F}: F_{1,60}=3.9, P=0.053$; compare with Table 1). There was a significant individual consistency in 11-KT and F levels of helpers (indicated by the significant random helper identity effects as reported in Table 1).

\section{Effects of status}

We compared helper males with single breeder males, which were size-matched at the start of the experiment and therefore no body mass effect can confound the results. Since there was

Table 3

Relationship between the large helper male's social interactions with the breeder male and non-group members, and the helper's hormone levels

\begin{tabular}{|c|c|c|c|c|c|c|c|c|c|c|c|c|}
\hline \multirow[t]{2}{*}{ Hormone $^{\mathrm{a}}$} & \multicolumn{2}{|c|}{ Period $^{\mathrm{b}}$} & \multicolumn{6}{|c|}{ Social interactions with the breeder male } & \multicolumn{4}{|c|}{ Aggression towards non-group members } \\
\hline & $F$ & $P$ & \multicolumn{2}{|c|}{ Submissive } & \multicolumn{2}{|c|}{ Affilitiave } & \multicolumn{2}{|c|}{$\begin{array}{l}\text { Received } \\
\text { aggression }\end{array}$} & \multicolumn{2}{|c|}{ Restrained } & \multicolumn{2}{|l|}{ Overt } \\
\hline \multicolumn{13}{|l|}{ Full models } \\
\hline $\mathrm{T}$ & 5.18 & 0.03 & 8.64 & 0.005 & 0.26 & 0.61 & 0.36 & 0.55 & 0.06 & 0.81 & 2.73 & 0.11 \\
\hline $11-\mathrm{KT}$ & 0.04 & 0.84 & 5.19 & 0.03 & 0.01 & 0.91 & 3.62 & 0.06 & 0.02 & 0.89 & 0.73 & 0.4 \\
\hline \multicolumn{13}{|c|}{ Final models } \\
\hline $\mathrm{T}^{\mathrm{c}}$ & 7.95 & 0.007 & 11.7 & 0.001 & & & & & & & & \\
\hline $11-\mathrm{KT}^{\mathrm{d}}$ & 0.45 & 0.5 & 6.15 & 0.02 & & & & & & & & \\
\hline $\mathrm{F}^{\mathrm{e}}$ & 3.62 & 0.06 & 11.88 & 0.001 & & & & & & & & \\
\hline
\end{tabular}

Results of separate GLMMs on each hormone are shown $(n=58)$, including all five types of social interactions (Full models) and the Final models including only the significant effect of submission towards the breeder male, as depicted in Fig. 4. Results were corrected for random period effects, and $d f=1$ for all independent variables.

\footnotetext{
${ }^{\mathrm{a}}$ In $\mathrm{pg} / \mathrm{fish} / \mathrm{h}$ and $\mathrm{ln}$-transformed before analyses.

${ }^{\mathrm{b}}$ Random effect.

${ }^{c}$ Estimates of the coefficients \pm SE: constant $6.321 \pm 0.177$, period one $-0.717 \pm 0.254$, period two 0 , submission score $-0.512 \pm 0.149$

${ }^{\mathrm{d}}$ Estimates of the coefficients \pm SE: constant $5.387 \pm 0.15$, period one $-0.146 \pm 0.217$, period two 0, submission score $-0.317 \pm 0.128$.

${ }^{\mathrm{e}}$ Estimates of the coefficients \pm SE: constant $6.169 \pm 0.136$, period one $0.373 \pm 0.196$, period two 0, submission score $-0.398 \pm 0.116$.
} 
no effect of the treatment on the hormone levels of helper males (see above), this factor was not included in the analysis. There was no difference in hormone levels between helper males and single breeder males (Fig. 4, Table 2).

Also in this analysis, there was a significant individual consistency in 11-KT and F levels of helpers and single breeders (indicated by the significant random effect of identity nested within status reported in Table 2).

\section{Effects of behaviour}

T, 11-KT and F were all significantly lower in large helper males that showed higher levels of submission towards the breeder male than helper males that were less submissive (Table 3, Fig. 5). Affiliative behaviour towards the breeder male,

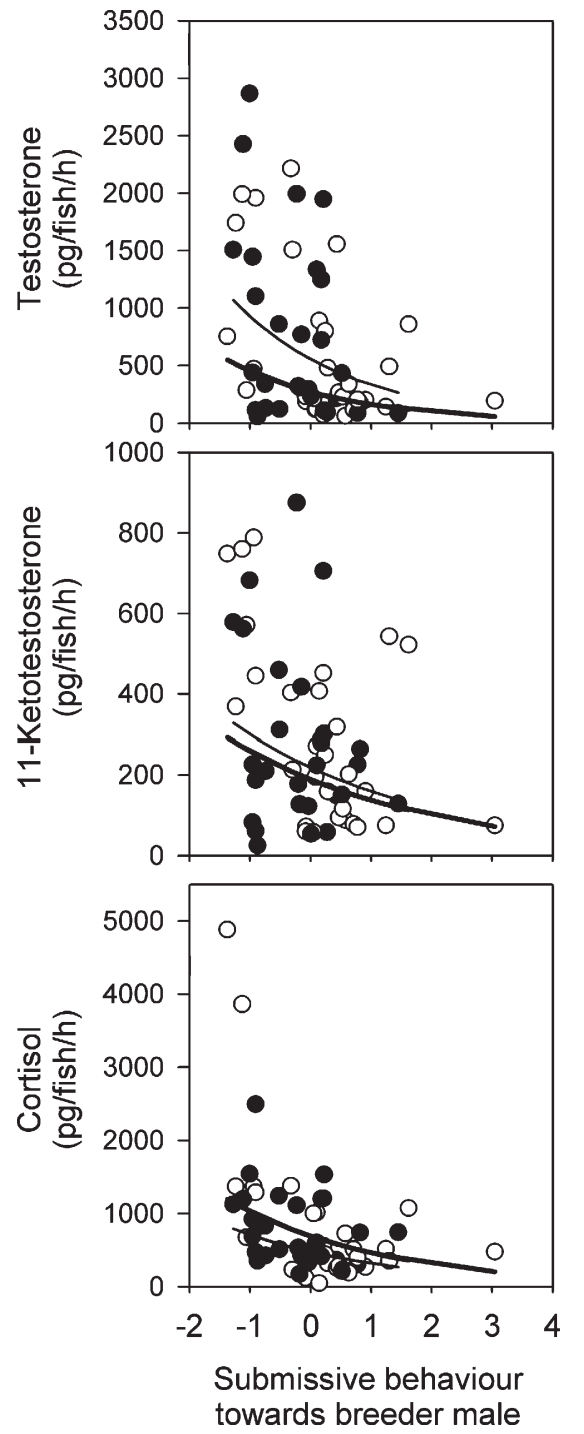

Fig. 5. Hormone levels of large helper males $(n=58)$ decreased with the level of submission shown by these helpers towards the breeder male, both in period 1 (white dots, bold lines) and period 2 (black dots, thin lines). The abscissa shows principal component scores for submission, i.e. summarising the frequency and duration of all submissive behaviours shown towards the breeder male during each period into one component (see text). For statistics, see Table 3. received aggression from the breeder male and overt and restrained aggression towards non-group members were all not related to hormone levels (Table 3). These comparisons are performed only within size-matched helper males and therefore no confounding body mass effect could be involved.

\section{Discussion}

The aim of the present study was to investigate the relationship between behaviour, social status, size differences and steroid hormone levels in a fish with alloparental brood care. In particular, we used a full-factorial repeated measures experimental design to test whether the levels of the stress hormone $\mathrm{F}$ and of the androgens $11-\mathrm{KT}$ and $\mathrm{T}$ in subordinate helper males depend on the size relationship between them and dominant breeder males. Such size relationships have proved to be of paramount importance for helper growth decisions (Heg et al., 2004b) and behaviour (Hamilton et al., 2005).

\section{Social status}

Our results show similar androgen levels in size-matched $N$. pulcher helper and breeder males. They reflect that helpers readily participate in reproduction (Dierkes et al., 1999), and they confirm data obtained in a different study (Oliveira et al., 2003). As N. pulcher male helpers modify growth (Heg et al., 2004b) and behaviour (Hamilton et al., 2005) in response to the size difference between them and breeder males, we expected that this would be reflected by respective modifications in steroid hormone levels. However, there were no differences in hormone levels when helpers were experimentally assigned to large breeder males or to small breeder males, respectively.

In contrast, in mammal and bird species with brood care helpers, dominant breeders often have higher androgen levels than non-breeding helpers, which has been interpreted as a sign of "psychological castration" of the subdominant by the dominant (Reyer et al., 1986; Schoech et al., 1991; Wingfield et al., 1991; Vleck and Brown, 1999; Oliveira et al., 2003). In Seychelles warblers, for example, only breeder males have elevated $\mathrm{T}$ levels during the sexually active period before egg laying, while helper males have low levels (Crommenacker van de et al., 2004). These results are also consistent with reproductive self-inhibition by the helper as a credible promise to avoid costly aggression from the breeder (Hamilton, 2004).

Systems are different where subordinates participate in reproduction: there, helpers and breeders show similar androgen levels. For example, dela Cruz et al. (2003), detected similar T levels in helper males and breeder males in the cooperatively breeding azure-winged magpie (Cyanopica cyanus). Furthermore, experimentally elevated plasma $\mathrm{T}$ did not affect the likelihood of becoming either a helper or a breeder. The authors concluded that helping in birds is a flexible behavioural option modulated in the short-term by social and ecological factors (de la Cruz et al., 2003). Similarly, breeder males and helper males had similar plasma $\mathrm{T}$ levels in red-cockaded woodpeckers (Picoides borealis), with both showing a peak during the copulation phase and a decrease during the incubating and 
nestling-provisioning phase (Khan et al., 2001). The authors of this study suggested that sexual inactivity in male helpers might be explained by behavioural suppression through the breeders rather than by physiological suppression/inhibition.

\section{Allometric scaling of hormone secretions}

It is standard practice to allometrically correct physiological measurements related to the overall metabolism of the focal animal, correcting for the overall body size of the individual (West and Brown, 2005). Therefore, hormones released into the water have been scaled to body mass in previous studies, dividing the excreted levels by body mass (Oliveira et al., 2003; Hirschenhauser et al., 2004). Although the method to measure hormone excretion levels in holding water has been validated by hormone injections (see Methods), it is as yet unclear whether standard allometrical scaling of the hormone levels as measured in the water is adequate to compare conspecific and heterospecific fishes of different sizes, and the possible allometric function is unknown. Our data showed no significant relationship between hormone excretion levels and body mass within fish of the same social status and different sizes (large breeder males and small breeder males). We therefore used excretion levels per fish and not per gram fish.

In the present study, we compared only similar sized fish (see also Scott and Sorensen, 1994; Vermeirssen and Scott, 1996; Ellis et al., 2004). Our results can therefore not be confounded by hormone level differences due to body size. In the only comparison between differently sized fish (small breeder males vs. large breeder males), we included $\ln$ [body mass] in the analysis to correct for potential influence on hormone levels. Again, this analysis showed no significant effect of body mass on hormone levels. We are confident therefore that the hormone excretion levels found in this study are not strongly influenced by differences in body mass.

\section{Egg laying}

We found no fluctuation in androgen levels of helper males and breeder males in $N$. pulcher between the situations with and without a brood. Androgens are normally high before breeding and low during the parenting stage in many bird and fish species, therefore a trade-off between androgens and parental care has been assumed. Exceptions are teleost species in which mating and parental phases are not separated in time and males may guard several clutches of different ages simultaneously (Oliveira et al., 1999), as occurs in our study species (Taborsky and Limberger, 1981; Limberger, 1983; Taborsky, 1984).

\section{Submissive behaviour as an honest signal of reduced reproductive capacity?}

T, 11-KT and F levels were significantly lower for helpers that were more submissive towards the breeder male within the 30 day period before the hormone measurements were taken, irrespective of treatment. These results indicate that there is a relationship between $\mathrm{F}$ levels (and therefore stress levels) and the behaviour of the helper, independent of size differences with the breeder. Helpers increased their submissive behaviour (a sign for a stronger conflict with the breeder male) when living with a small breeder male (Hamilton et al., 2005) and submissive behaviour is used to appease breeders (Bergmüller and Taborsky, 2005; Bergmüller et al., 2005). As F levels of helpers which are apparently in stronger conflict with the breeder are lower than in helpers experiencing less agonistic interactions (where submissive behaviour would be required), we conclude that submissive behaviour is an important mechanism to alleviate stressful situations for helpers in breeder-helper conflicts (see also Bergmüller and Taborsky, 2005). Interestingly, submissive behaviour is energetically very expensive (Grantner and Taborsky, 1998). Other behaviours like affiliative behaviour towards the breeder male, received aggression from the breeder male and overt and restrained aggression towards conspecific neighbours all were not related to hormone levels.

Moreover, hormones involved in dominance and reproduction ( $\mathrm{T}$ and 11-KT) were reduced in helpers that were more submissive compared to similar sized helpers that were less submissive. This suggests that submissive behaviour may be an honest signal to male breeders: helpers signal a lower reproductive risk to breeders by behaving submissively (see Dierkes et al., 1999; Skubic et al., 2004) compared to helpers which showed less submissive behaviour, which would reflect higher androgen levels. The low androgen levels combined with submissive behaviour may reflect a reproductive self-inhibition by male helpers as a credible promise to prevent costly aggression from the breeder (Hamilton, 2004). Hence, submissive behaviour may be an honest signal for two reasons: firstly, it has been shown to be energetically costly and constitutes a considerable part of the helpers' behavioural energy budget (Grantner and Taborsky, 1998; Taborsky and Grantner, 1998). Secondly, it reveals a lower reproductive potential compared to less submissive helpers as shown by our study, which means less costs to male breeders by reproductive competition through helpers (Dierkes et al., 1999).

Helping behaviour in the form of defence of the territory was not related to androgen levels and therefore cannot be considered an honest signal relative to reproductive capacity. Even if helping is used by the helpers to be allowed to stay in the territory (Balshine-Earn et al., 1998; Bergmüller and Taborsky, 2005), apparently it does not reveal the level of the helper's capacity to participate in reproduction. Different behaviours of helpers may serve different purposes: helping behaviour is used as payment to be accepted in the territory (Bergmüller and Taborsky, 2005), while submissive behaviour may be used primarily to appease breeders by honestly revealing the helpers reproductive capacity.

Interestingly, speed of growth cannot be considered an honest signal for reduced reproductive capacity, as different growth rates did not relate to androgen levels in helper males. The growth adjustments shown by helpers in dependence of breeder size (Heg et al., 2004b) must therefore be considered as an appeasing signal to breeders to reduce the potential for behavioural conflict, but without signalling the reproductive capacity of the helpers. 


\section{Acknowledgments}

We thank R. Eggler and P. Stettler for technical assistance, and our colleagues from the Behavioural Ecology and Evolutionary Ecology Departments, University of Bern, for feedback on the design of the experiment. We thank Tania Oliveira for technical assistance during the hormonal analyses. Rick Bruintjes and the anonymous referees provided helpful comments on the manuscript. The project was supported by the Swiss National Science Foundation (SNSF grants 3100-064396 and 3100A0-105626 to M.T. and SNSF grants 3234-069260.02/ 1 and PIOIA-103213 to N.B.), by the Stiftung zur Förderung der wissenschaftlichen Forschung an der Universität Bern to N.B. and by The Plurianual Program (R\&D Unit 331/2004) from the Portuguese Foundation for Science and Technology, VCT-POCTI/PEDER to R.F.O.

\section{References}

Balshine-Earn, S., Neat, F.C., Reid, H., Taborsky, M., 1998. Paying to stay or paying to breed? Field evidence for direct benefits of helping behaviour in a cooperatively breeding fish. Behav. Ecol. 9 (5), 432-438.

Balshine, S., Leach, B., Neat, F., Reid, H., Taborsky, M., Werner, N., 2001. Correlates of group size in a cooperatively breeding cichlid fish (Neolamprologus pulcher). Behav. Ecol. Sociobiol. 50, 134-140.

Bergmüller, R., Taborsky, M., 2005. Experimental manipulation of helping in a cooperative breeder: helpers "pay to stay" by pre-emptive appeasement. Anim. Behav. 69, 19-28.

Bergmüller, R., Heg, D., Taborsky, M., 2005. Helpers in a cooperatively breeding cichlid stay and pay or disperse and breed, depending on ecological constrains. Proc. R. Soc. B 272, 325-331.

Brouwer, L., Heg, D., Taborsky, M., 2005. Experimental evidence for helper effects in a cooperatively breeding cichlid. Behav. Ecol. 16 (3), 667-673.

Brown, J.L., 1987. Helping and Communal Breeding in Birds. Priceton Univ. Press, Princeton.

Buchner, A.S., Sloman, K.A., Balshine, S., 2004. The physiological effects of social status in the cooperatively breeding cichlid Neolamprologus pulcher. J. Fish Biol. 65, 1080-1095.

Buston, P., 2003. Size and growth modification in clownfish. Nature 424, 145-146.

Cardwell, J.R., Sorensen, P.W., Van Der Kraak, G.J., Liley, N.R., 1996. Effect of dominance status on sex hormone levels in laboratory and wild-spawning male trout. Gen. Comp. Endocrinol. 101, 333-341.

Cockburn, A., 1998. Evolution of helping behaviour in cooperatively breeding birds. Annu. Rev. Ecol. Syst. 29, 141-177.

Crawley, M.J., 2003. Statistical Computing: An Introduction to Data Analysis Using S-Plus. John Wiley and Sons Ltd., Chichester.

Crommenacker van de, J., Richardson, D.S., Groothuis, T.G.G., Eising, C.M., Dekker, A.J., Komdeur, J., 2004. Testosterone, cuckoldry rist and extra-pair opportunities in the Seychelles warbler. Proc. R. Soc. London, Ser. B Biol. Sci. 271, 1023-1031.

de la Cruz, C., Solís, E., Valencia, J., Chastel, O., Sorci, G., 2003. Testosterone and helping behaviour in the azure-winged magpie (Cyanopica cyanus) natural covariation and an experimental test. Behav. Ecol. Sociobiol. 55, $103-111$.

Dierkes, P., Taborsky, M., Kohler, U., 1999. Reproductive parasitism of broodcare helpers in a cooperatively breeding fish. Behav. Ecol. 10 (5), 510-515.

Dierkes, P., Heg, D., Taborsky, M., Skubic, E., Achmann, R., 2005. Genetic relatedness in groups is sex-specific and declines with age of helpers in a cooperatively breeding cichlid. Ecol. Lett. 8, 968-975.

Ellis, T., James, J.D., Steward, C., Scott, A.P., 2004. A non-invasive stress assay based upon measurement of free $\mathrm{F}$ released into the water by rainbow trout. J. Fish Biol. 65, 1233-1252.

Grantner, A., Taborsky, M., 1998. The metabolic rates associated with resting, and with the performance of agonistic, submissive and digging behaviours in the cichlid fish Neolamprologus pulcher (Pisces: Cichlidae). J. Comp. Physiol., B 168, 427-433.

Hamilton, I.M., 2004. A commitment model of reproductive inhibition in cooperatively breeding groups. Behav. Ecol. 15 (4), 585-591.

Hamilton, I.M., Heg, D., Bender, N., 2005. Size differences within a dominance hierarchy influence conflict and help in a cooperative breeding cichlid. Behaviour 142, 1591-1613.

Hatchwell, B.J., Komdeur, J., 2000. Ecological constraints, life history traits and the evolution of cooperative breeding. Anim. Behav. 59, 1079-1086.

Heg, D., Bachar, Z., Brouwer, L., Taborsky, M., 2004a. Predation risk in an ecological constraint for helper dispersal in a cooperatively breeding cichlid. Proc. R. Soc. B 271, 2367-2374

Heg, D., Bender, N., Hamilton, I.M., 2004b. Strategic growth decisions in helper cichlids. Proc. R. Soc. London, Ser. B Biol. Sci. (Suppl.) 271, 505-508.

Heg, D., Brouwer, L., Bachar, Z., Taborsky, M., 2005. Large group size yields group stability in the cooperatively breeding cichlid Neolamprologus pulcher. Behaviour 142, 1615-1641.

Hirschenhauser, K., Ros, A.F.H., Carneiro, L.A., Oliveira, T., Silva, A., Canario, A.V.M., Oliveira, R.F., 2002. Non-invasive hormone assessment from fish holding water. Adv. Ethol. 37, 139

Hirschenhauser, K., Taborsky, M., Oliveira, T., Canario, A.V.M., Oliveira, R.F., 2004. A test of the "challenge hypothesis" in a cichlid fish: simulated partner and territory intruder experiments. Anim. Behav. 68, 741-750.

Khan, M.Z., McNabb, F.M.A., Walters, J.R., Sharp, P.J., 2001. Patterns of testosterone and prolactin concentrations and reproductive behaviour of helpers and breeders in the cooperatively breeding red-cockaded woodpecker (Picoides borealis). Horm. Behav. 40, 1-13.

Kime, D.E., Manning, N.J., 1982. Seasonal patterns of free and conjugate androgens in the brown trout, Salmo trutta. Gen. Comp. Endocrinol. 48, 222-231.

König, W.D., Dickinson, J.L., 2004. Ecology and Evolution of Cooperative Breeding in Birds. Cambridge Univ. Press, Cambridge.

Kotrschal, K., Hirschenhauser, K., Möstl, E., 1998. The relationship between social stress and dominance is seasonal in greylag geese. Anim. Behav. 55, 171-176.

Limberger, D., 1983. Pairs and harems in a cichlid fish, Lamprologus brichardi. Zeitschr. Tierpsychol. 62, 115-144.

Moriwaki, T., Kobayashi, M., Aida, K., Hanyu, I., 1991. Changes in plasma gonado-tropin and steroid hormone levels during ovulation induced by HCG treatment in female goldfish. Nippon Suisan Gakkaishi $57,41-43$

Oliveira, R.F., 2004. Social modulation of androgens in vertebrates: mechanisms and function. Adv. Stud. Behav. 34, 165-239.

Oliveira, R.F., Almada, V.C., Canario, A.V.M., 1996. Social modulation of sex steroid concentrations in the urine of male cichlid fish Oreochromis mossambicus. Horm. Behav. 30, 2-12.

Oliveira, R.F., Canario, A.V.M., Bshary, R., 1999. Hormones, behaviour and conservation of littoral fishes: current status and prospects for future research. In: Almada, V.C., Oliveira, R.F., Gonçalves, E.J. (Eds.), Behaviour and Conservation of Littoral Fishes. ISPA, Lisbon.

Oliveira, R.F., Almada, V.C., Gonçalves, E.J., Forsgren, E., Canario, A.V.M., 2001a. Androgen levels and social interactions in breeding males of the peacock blenny. J. Fish Biol. 58, 897-908.

Oliveira, R.F., Lopes, M., Carneiro, L.A., Canario, A.V.M., 2001b. Watching fights raises fish hormone levels. Nature 409, 475.

Oliveira, R.F., Canario, A.V.M., Grober, M.S., Santos, S., 2001c. Endocrine correlates of male polymorphism and alternative reproductive tactics in the azorean rock-pool blenny, Parablennius sanguinolentus parvicornis. Gen. Comp. Endocrinol. 121, 278-288.

Oliveira, R.F., Hirschenhauser, K., Canario, A.V.M., Taborsky, M., 2003. Androgen levels of reproductive competitors in a co-operatively breeding cichlid. J. Fish Biol. 63, 1615-1620.

Reyer, H.U., Dittami, J.P., Hall, M.R., 1986. Avian helpers at the nest: are they psychologically castrated? Ethology 71, 216-228.

Riedman, M.L., 1982. The evolution of alloparental care and adoption in mammals and birds. Qu. Rev. Biol. 57, 405-435.

Ros, A.F.H., Bruintjes, R., Santos, R.S., Canario, A.V.M., Oliveira, R.F., 2004. The role of androgens in the trade-off between territorial and parental behaviour in the Azorean rock-pool blenny, Parablennius parvicornis. Horm. Behav. 46 (4), 491-497. 
Schoech, S.J., Mumme, R.L., Moore, M.C., 1991. Reproductive endocrinology and mechanisms of breeding inhibition in cooperatively breeding Florida scrub jays (Aphelocoma c. coerulescens). Condor 93, 354-364.

Schoech, S.J., Reynolds, S.J., Boughton, R.k., 2004. Endocrinology. In: Koenig, W.D., Dickinson, J.L. (Eds.), Ecology and Evolution of Cooperative Breeding in Birds. Cambridge University Press, Cambridge, pp. 128-141.

Scott, A.P., Sorensen, P.W., 1994. Time course and release of pheromonally active gonadal steroids and their conjugates by ovulatory goldfish. Gen. Comp. Endocrinol. 96, 309-323.

Scott, A.P., MacKenzie, D.S., Stacey, N.E., 1984. Endocrine changes during natural spawning in the white sucker, Catostomus commersoni: II. Steroid hormones. Gen. Comp. Endocrinol. 56, 349-359.

Skubic, E., Taborsky, M., McNamara, JM., Houston, A.I., 2004. When to parasitize? A dynamic optimization model of reproductive strategies in a cooperative breeder. J. Theor. Biol. 227 (4), 487-501.

Solomon, N.G., French, J.A., 1997. Cooperative Breeding in Mammals. Cambridge Univ. Press, Cambridge.

Stiver, K.A., Dierkes, P., Taborsky, M., Gibbs, H.L., Balshine, S., 2005. Relatedness and helping in fish: examining the theoretical predictions. Proc. R. Soc. B 272, 1593-1599.

Taborsky, M., 1984. Broodcare helpers in the cichlid fish Lamprologus brichardi: their costs and benefits. Anim. Behav. 32, 1236-1252.

Taborsky, M., 1985. Breeder-helper conflict in a cichlid fish with broodcare helpers: an experimental analysis. Behaviour 95, 45-75.
Taborsky, M., 1994. Sneakers, satellites, and helpers: parasitic and cooperative behaviour in fish reproduction. Adv. Study Behav. 23, 1-100.

Taborsky, M., Grantner, A., 1998. Behavioural time-energy budgets of cooperatively breeding Neolamprologus pulcher (Pisces: Cichlidae). Anim. Behav. 56, 1375-1382.

Taborsky, M., Limberger, D., 1981. Helpers in fish. Behav. Ecol. Sociobiol. 8, $143-145$.

Vermeirssen, E.L.M., Scott, A.P., 1996. Excretion of free and conjugated steroids in rainbow trout (Oncorhynchus mykiss): evidence for branchial excretion of the maturation-inducing steroid, 17,20ß-Dihydroxy-4-pregnen3-one. Gen. Comp. Endocrinol. 101, 180-194.

Vleck, C.M., Brown, J.L., 1999. Testosterone and social and reproductive behaviour in Aphelocoma jays. Amin. Behav. 58, 943-951.

West, G.B., Brown, J.H., 2005. The origin of allometric scaling laws in biology from genomes to ecosystems: towards a quantitative unifying theory of biological structure and organization. J. Exp. Biol. 208, 1575-1592.

Wilson, E.O., 1993. Sociobiology. Belknap Press, Cambridge.

Wingfield, J.C., Hegner, R.E., Dufty Jr., A.M., Ball, G.F., 1990. The "Challenge Hypothesis": theoretical implications for patterns of testosterone secretion, mating systems, and breeding strategies. Am. Nat. 136, 829-846.

Wingfield, J.C., Hegner, R.H., Lewis, D.M., 1991. Circulating levels of luteinizing hormone and steroid hormones in relation to social status in the cooperatively breeding white-browed sparrow weaver, Plocepasser mahali. J. Zool. 225, 43-58. 